\title{
IMPACT FACTORS OF KNOWLEDGE SHARING INTENTION OF IT EMPLOYEES IN VIETNAM - AN INTEGRATED APPROACH
}

\author{
PHAM QUOC TRUNG \\ Ho Chi Minh City University of Technology, Vietnam National University, HCMC - pqtrung@ hcmut.edu.vn \\ HO BA THANG \\ FIS - ERP CO., LTD - makemewonder123@gmail.com
}

(Received: February 21, 2017; Revised: March 23, 2017; Accepted: April 10, 2017)

\begin{abstract}
In knowledge era, knowledge sharing has been becoming an essential issue to knowledge-based organizations, such as IT businesses. However, knowledge sharing among workers in IT organizations is not efficient in reality. Especially, in a developing country like Vietnam, there is a lack of research in this topic. Therefore, this research tries to identify and to measure the impact of those factors on knowledge sharing intention of employees in IT industry. Unlike previous studies, this research integrated factors of Theory of Planned Behavior (TPB) and other factors of organization environment and ICT to explore their impacts on knowledge sharing intention. Using Convenience sampling method, 257 valid samplings were collected from organizations in IT industry in HCMC. The scale was tested by Cronbach's Alpha, EFA analysis methods. Based on regression analysis, the factor affecting on knowledge sharing intention of employees was sorted by descending order, including: affiliation and innovativeness in organization, attitude towards knowledge and subjective norms, perceived behavioral control. Besides, the knowledge sharing intention of employees is also indirectly affected by factors: anticipated reciprocal relationship and fairness in organization and support of ICT. The results of ANOVA analysis shows that there is a marked difference of knowledge sharing intention between managers and employees. Based on these results, some suggestions for facilitating knowledge sharing between employees in IT industry are proposed.
\end{abstract}

Keywords: knowledge sharing; IT industry; organizational climate; knowledge management; Vietnam.

\section{Introduction}

In knowledge economy, the development of any business depends not only on tangible assets, but also on intangible assets, such as: human resource, or knowledge resource. Knowledge becomes one sure source of business success (Nonaka, 1995). Knowledge management $(\mathrm{KM})$ helps to create values for business based on their knowledge resources (Dalkir, 2005). In KM, knowledge sharing is very important in facilitating the knowledge flow within the organization, especially tacit knowledge.

In Vietnam, recently, many businesses paid attention to $\mathrm{KM}$ approach and tried to encourage knowledge sharing within their organization. Some businesses also applied KM step by step and got some benefits (PCWorld, 2008). For IT industry, a knowledge intensive area, knowledge sharing becomes more and more important for ensuring the business success and helping their employees to keep up with the fast changing of technology.

According to a report of Mercer (Baomoi, 2013), a human resource consulting company, there is a high rate $(>15 \%)$ of employees' job change in high tech area, especially IT sector, in Vietnam. Therefore, IT businesses have to focus on KM activity and encouraging knowledge sharing between their employees for maintaining the developing of their businesses.

However, knowledge sharing is a challenged task for any business (Bock \& 
Kim, 2001). Determining impact factors of knowledge sharing intention is necessary for encouraging knowledge sharing behavior between employees. There are several previous researches about knowledge sharing intention, but these researches focused on single aspect of individual, organization or technology. Therefore, there is a need to integrate all of above aspects to understand the overall impact on knowledge sharing intention between employees from different viewpoints.

Moreover, in Vietnam context, there are very few studies on knowledge sharing in IT industry, therefore, the topic "Impact factors of knowledge sharing intention of IT employees in Vietnam - an integrated approach" is conducted. This research aims to (1) identify impact factors of knowledge sharing intention, (2) measure the impact level of each factor on knowledge sharing intention of IT employees in Vietnam, and (3) suggest some managerial implications for encouraging knowledge sharing between IT employees in Vietnam.

\section{Literature review}

\subsection{Main concepts}

Knowledge is defined as "justified belief" (Nonaka et al., 1995). Nonaka also clarified that knowledge is a dynamic process of human beings for proving personal belief and truth. From the viewpoint of science of cognition, knowledge is related to data and information by 2 dimensions: understanding and context independence (Serban et al., 2002). Besides, Polanyi (1966) classified knowledge into 2 groups: (1) tacit knowledge, which is located in human brain and difficult to capture, and (2) explicit knowledge, which is easier to capture and to present in some form.

Knowledge management is a process of realizing, sharing, using and practicing knowledge inside of an organization (Choi \& Lee, 2002). For managing knowledge effectively, a knowledge management process should be established. Dalkir (2005) combined previous $\mathrm{KM}$ cycles and introduced an integrated KM cycle, including 3 steps: (1) knowledge capture and creation, knowledge sharing and dissemination, and (3) knowledge acquisition and application.

Knowledge sharing is the activity to disseminate knowledge between people within an organization. This is one of the most important and difficult steps in KM process because people worry of losing power in sharing their knowledge (Tsai et al., 2013).

Organizational climate or organizational culture refers to organizational environment, both physical and spiritual form. Organizational climate relates to organizational psychology and behavior science (Castro \& Martins, 2010). It shows the feelings and thinking of organizational members about their working environment in a period of time. Therefore, it is temporary and subjective (Bock et al., 2005). While, organizational culture relates to values, trust, norms of organizational members (Castro \& Martins, 2010). Organizational climate is used in this research context.

\subsection{Theoretical background \& related researches}

Theory of Planned Action (TPB) developed by Ajzen (1991), which is extended from Theory of Rationed Action (TRA). TPB model suggested 3 factors impacting on intention and behavior of a person, including: attitude, subjective norm (similar to TRA), and perceived behavioral control (new factor). TPB model is very popular, and used mostly in social science for understanding people's intention and behavior.

Related researches could be summarized in the following table. 


\section{Table 1}

Related researches in knowledge sharing

\begin{tabular}{|c|c|c|c|c|}
\hline Author & Sample & Respondent & Factors & Comments \\
\hline $\begin{array}{l}\text { Tran \& } \\
\text { Pham } \\
(2012)\end{array}$ & 210 & $\begin{array}{l}\text { Doctor in } \\
\text { HCMC }\end{array}$ & $\begin{array}{l}\text { - Attitude toward knowledge sharing } \\
\text { - Perceived behavioral control } \\
\text { - Subjective norm } \\
\text { - Reciprocal relationship } \\
\text { - Believe in personal knowledge } \\
\text { - Believe in colleague }\end{array}$ & $\begin{array}{l}\text { Confirm strong impact } \\
\text { of factors in TPB on } \\
\text { knowledge sharing } \\
\text { intention of doctors in } \\
\text { Vietnamese hospital. } \\
\text { Limitation: lack of } \\
\text { organizational culture } \\
\text { related factors. }\end{array}$ \\
\hline $\begin{array}{c}\text { Joseph } \\
\& \\
\text { Jacob } \\
(2011)\end{array}$ & 125 & $\begin{array}{l}\text { IT experts in } \\
\text { India }\end{array}$ & $\begin{array}{l}\text { - Attitude toward knowledge sharing } \\
\text { - Subjective norm } \\
\text { - Reward } \\
\text { - Reciprocal relationship } \\
\text { - Organization climate: fairness, } \\
\text { innovativeness, affiliation }\end{array}$ & $\begin{array}{l}\text { Based on Bock et al. } \\
(2005), \text { conducted in IT } \\
\text { industry, this research } \\
\text { confirmed the impact of } \\
\text { organizational climate } \\
\text { and other factors in } \\
\text { TRA on knowledge } \\
\text { sharing intention. } \\
\text { Limitation: lack of } \\
\text { barrier factors of } \\
\text { knowledge sharing. }\end{array}$ \\
\hline $\begin{array}{l}\text { Borges } \\
(2012)\end{array}$ & 143 & $\begin{array}{c}\text { IT experts in } \\
\text { US }\end{array}$ & $\begin{array}{l}\text { - Personal factors: extraversion, } \\
\text { emotional stability, } \\
\text { conscientiousness } \\
\text { - Organizational culture: supportive, } \\
\text { team-oriented, } \\
\text { - Social Network }\end{array}$ & $\begin{array}{l}\text { The result confirmed the } \\
\text { impact of personal } \\
\text { factors, organizational } \\
\text { culture, and social } \\
\text { network on knowledge } \\
\text { sharing intention. } \\
\text { Limitation: focus on IT } \\
\text { experts, tacit } \\
\text { knowledge, and small } \\
\text { sample size. }\end{array}$ \\
\hline $\begin{array}{l}\text { Tsai et } \\
\text { al. } \\
(2013)\end{array}$ & 251 & $\begin{array}{c}\text { IT expert in } \\
\text { Taiwan }\end{array}$ & $\begin{array}{l}\text { - Attitude toward knowledge sharing } \\
\text { - Perceived organizational support } \\
\text { - Organizational trust } \\
\text { - Reciprocal relationship } \\
\text { - Self-belief }\end{array}$ & $\begin{array}{l}\text { The result showed that } \\
\text { factors in social } \\
\text { exchange theory have an } \\
\text { impact on knowledge } \\
\text { sharing intention. } \\
\text { Limitation: lack of } \\
\text { factors related to } \\
\text { organizational culture, } \\
\text { and psychological } \\
\text { aspects. }\end{array}$ \\
\hline
\end{tabular}

Previous studies explored impact factors on knowledge sharing intention in different areas, such as: construction, health care, education, ICT industry, and so on. However, each study focused on individual aspect of the impact such as: personal attitude, 
organizational climate, or technology. There is a need for integrating all of these aspects for having an overall understanding of knowledge sharing intention inside of an organization such as IT companies in Vietnam.

\subsection{Research model and hypotheses}

Most of the previous studies in knowledge sharing are based on TRA or TPB model with some modifications. Therefore, TPB model is chosen as a background for this research. Besides, previous analysis results showed that organizational climate is very important in understanding knowledge sharing intention. So, the proposed model of Bock et al. (2005) is suitable because of its combination of psychological aspect and organizational environment aspect. Moreover, this research aims at IT industry in Vietnam, therefore, another research of Joseph and Jacob (2011) in ICT industry is considered to complement to the proposed model. However, both studies of Bock et al. (2005) and Joseph and Jacob (2011) didn't mention about Perceived behavioral control factor (which exists in TPB model). This factor would be added to the proposed model.

On the other hand, according to Hendriks (1999), ICT is a motivation for knowledge sharing by reducing barriers (both space and time) for knowledge sharing behavior (Zhang $\& \mathrm{Ng}, 2013)$. Zhang and Ng (2013) also put ICT factor in their model for measuring its impact on knowledge sharing intention. Another research of Alamgir and Ahmed (2011) also confirmed the affection of ICT on knowledge sharing capability. Therefore, to have an integrated framework for exploring impact factors on knowledge sharing intention from different aspects, ICT factor should be added to the proposed model.

In general, knowledge sharing intention of IT employees is affected by their attitude toward knowledge sharing, subjective norm, and perceived behavioral control. Attitude is determined by rewards and reciprocal relationship, and subjective norm is affected by organizational climate (including: fairness, affiliation, and innovativeness). And finally, perceived behavioral control is determined by ICT support. The proposed integrated model could be summarized in the following figure.

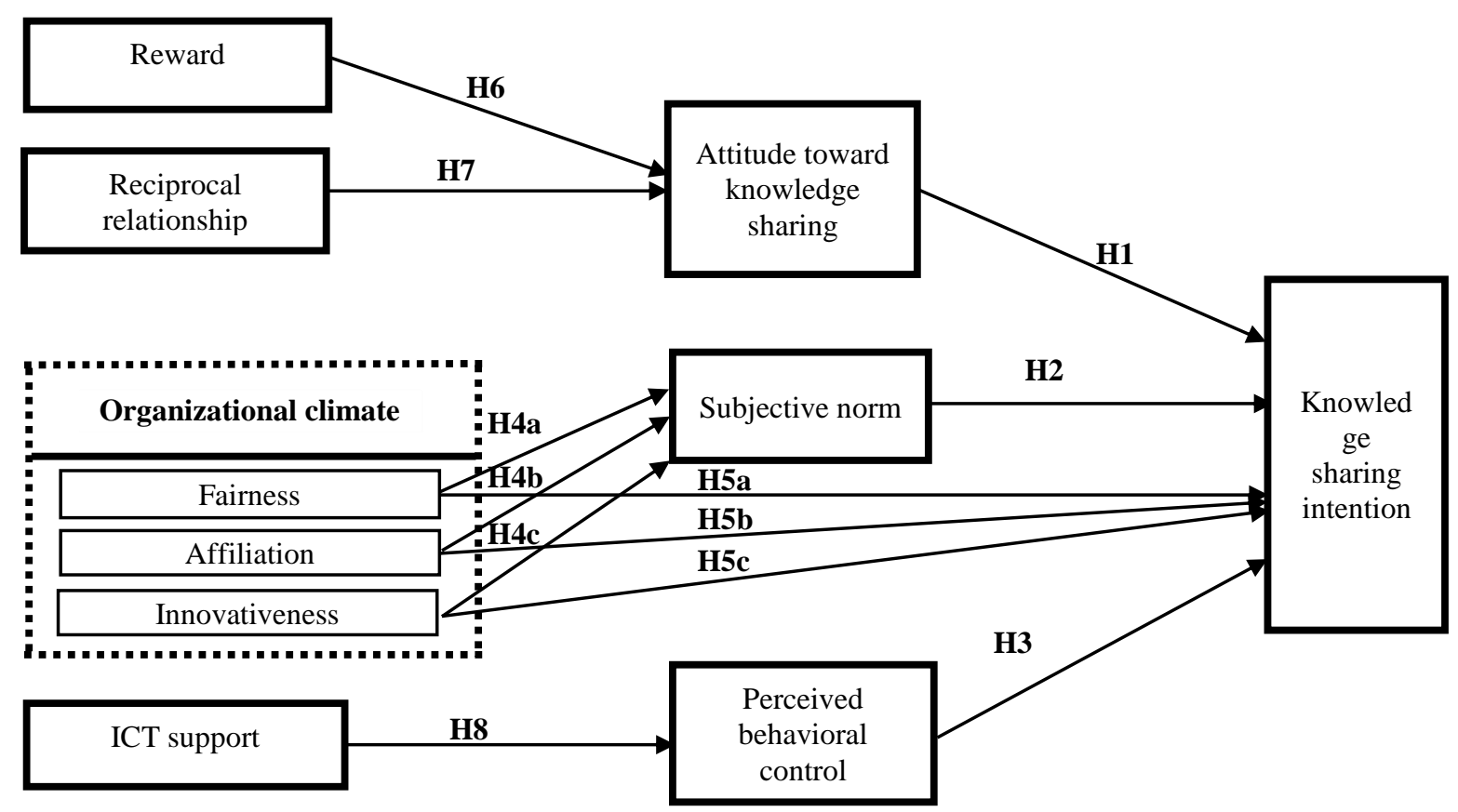

Figure 1. The proposed research model 


\section{Reward}

Rewards are benefits or incentives that employees expect to receive in sharing their knowledge, such as: salary, promotion, or other benefits (Dong et al., 2010). Knowledge sharing is most likely to occur when employees perceive that incentives exceed costs (Bock et al., 2005). Joseph and Jacob (2011) confirmed that rewards have an indirect effect on knowledge sharing intention of IT employees through their attitude toward knowledge sharing.

\section{Reciprocal relationship}

Reciprocal relationship refers to the expectation of improving the mutual relationships in knowledge sharing (Bock et al., 2005). Employees who believe their mutual relationships with others can improve through their knowledge sharing are likely to have positive attitudes toward knowledge sharing. Therefore, it has an indirect impact on knowledge sharing intention.

\section{Attitude toward knowledge sharing}

According to TRA and TPB model, intention to engage in a behavior is determined by an individual's attitude toward that behavior (Ajzen, 1991). Here, attitude toward knowledge sharing is defined as the degree of one's positive feelings about sharing one's knowledge. Bock et al. (2005) showed that attitude toward knowledge sharing plays an intermediate role between rewards, reciprocal relationship and knowledge sharing intention.

\section{Organizational climate}

According to Patterson et al. (2005), organizational climate refers to the feelings of organizational members about working environment (policies, procedures, practices...). Organizational climate has an impact on sharing and learning ability of employees, helps them to learn new knowledge and skills, and encourages creativity and innovation (Joseph \& Jacob, 2011). There are three aspects of organizational climate as being particularly conducive to knowledge sharing: fairness, innovativeness, and affiliation.
Fairness, which reflects the perception that organizational practices are equitable and neither arbitrary nor capricious, both builds trust between members and serves to overcome the public good dilemma associated with knowledge sharing. Innovativeness, which reflects the perception that change and creativity are actively encouraged and rewarded, emphasizes learning, open information flows, and reasoned risk-taking. Finally, affiliation, defined as the perception of a sense of togetherness among an organization's members, reflects the caring and pro-social behavior critical to inducing an organization's members to help one another. In general, organizational climate affects individuals' intention to share knowledge in two ways: (1) has an indirect impact on knowledge sharing intention through subjective norms (Ajzen, 1991); (2) directly influence individuals' intentions to share knowledge (Joseph and Jacob, 2011).

\section{Subjective norm}

The subjective norm construct, defined as perceived social pressure to perform or not perform a behavior (Ajzen, 1991), has received considerable empirical support as an important antecedent to behavioral intention. Therefore, based on TPB, the pressure from managers, colleagues, and friends has an impact on employees' knowledge sharing intention.

\section{ICT support}

ICT provides methods and applications for knowledge sharing activities, such as: groupware, intranet, database, video conference... The quality, accessibility and availability of ICT devices may have an impact on knowledge sharing ability. ICT support may help to improve efficiency and effectiveness of knowledge sharing. Therefore, it may have a direct impact on perceived behavioral control, and an indirect impact on knowledge sharing intention (Zhang \& Ng, 2013).

\section{Perceived behavioral control}

Perceived behavioral control is employees' 
cognition about the difficulty level of the knowledge sharing behavior (Ajzen, 1991). This refers to opportunities, tools or resources for sharing knowledge between employees (Zhang \& Ng, 2013).

Based on above analysis, 8 hypotheses have been proposed as follows:

Hypothesis H1: Attitude toward knowledge sharing has a positive impact on knowledge sharing intention.

Hypothesis H2: Subjective norm has a positive impact on knowledge sharing intention.

Hypothesis H3: Perceived behavioral control has a positive impact on knowledge sharing intention.

Hypothesis H4a: Fairness of organizational climate has a positive impact on subjective norm.

Hypothesis H4b: Affiliation of organizational climate has a positive impact on subjective norm.

Hypothesis H4c: Innovativeness of organizational climate has a positive impact on subjective norm.

Hypothesis H5a: Fairness of organizational climate has a positive impact on knowledge sharing intention.

Hypothesis H5b: Affiliation of organizational climate has a positive impact on knowledge sharing intention.

Hypothesis H5c: Innovativeness of organizational climate has a positive impact on knowledge sharing intention.

Hypothesis H6: Reward has a positive impact on attitude toward knowledge sharing.

Hypothesis H7: Reciprocal relationship has a positive impact on attitude toward knowledge sharing.

Hypothesis H8: ICT support has a positive impact on perceived behavioral control of knowledge sharing.

This research also analyze the impact of demographic factors on knowledge sharing intention of IT employees, such as: gender, years of experience, age, education, and position.

\section{Research method}

This research is conducted by 2 phases: (1) primary qualitative method for revising measurement scale based on interviews, and (2) quantitative method for testing the model through several tools: Cronback alpha test, EFA, and regression analysis.

The original measurement scale based mostly on Bock et al. (2005), using 5 levels Likert scale. Then, it is translated into Vietnamese and revised based on interviewing with 11 experts in IT, management, and economics. Some main contribution of primary qualitative step could be summarized as follows: combine 2 questions in "knowledge sharing intention", and combine 2 questions in "attitude..." because of its similarity, and add 1 more variable in Reward factor. Some minor modifications in spellings, grammars and writing styles relating to IT industry have also been made.

The sample size for quantitative step must be 5 times greater than number of observation variables. Therefore, the minimum sample size must be 200 ( 40 x 5). Data collection method is convenience sampling method, with a combination of online and offline survey. Collected data will be processed by SPSS software, through: Cronbach alpha test, EFA, correlation analysis, multiple regression analysis, and ANOVA analysis.

\section{Analysis results}

Number of questionnaires sent is 300 . Number of validated samples (collected from both online and offline) is 257 .

\subsection{Descriptive statistics}

- By gender: there are 68 female respondents $(26 \%)$ and 189 male respondents $(74 \%)$. It is the same with the population rate between male and female in IT industry. According to Thoi-bao vi-tinh Sai-Gon (2013), 30\% of IT employees in Vietnam are female.

- By age: the highest group belong to 2129 (202 respondents, $79 \%)$, the next group is 30-34 (32 respondents, 12\%), then $35-39$ (16 respondents, 6\%), and the last group is 
$>40$ (7 respondents, 3\%). Previous report (Le, 2012) showed that most of IT employees are young people ( $70 \%$ of IT employees less than 30 years old).

- By educational level: most of respondents get a bachelor degree (202 respondents, $79 \%$ ), the second group is college, secondary school (40 respondents, $15 \%)$, and the last group is post-graduate level (15 respondents, 6\%).

- By position: the highest group is employees (201 respondents, 78\%), then group leader (42 respondents, 16\%), then head of department (10 respondents, $4 \%$ ), and then, board of management (4 respondents, $2 \%$ ).

- By years of working: the highest group is $0-3$ years (151 respondents, $59 \%$ ), the next group is 3-6 years (47 respondents, 18\%), then $6-9$ years (39 respondents, $15 \%$ ), then 9 -12 years (16 respondents, $6 \%$ ) and finally, $>12$ years (4 respondents, $2 \%$ ).

\subsection{Cronbach's Alpha analysis}

The table below showed that Cronbach's alpha coefficients of all factors are reliable (Cronbach's Alpha $>0.6)$ after removing unqualified variables (Item-Total Correlation $<0.3)$.

\section{Table 2}

Cronbach's Alpha analysis result

\begin{tabular}{|l|c|c|}
\hline \multicolumn{1}{|c|}{ Measurement scale } & Cronbach's Alpha & $\begin{array}{c}\text { Corrected Item-Total } \\
\text { correlations }\end{array}$ \\
\hline $\begin{array}{l}\text { Attitude toward knowledge } \\
\text { sharing }\end{array}$ & 0.692 & $0.428-0.518$ \\
\hline Subjective norm & 0.711 & $0.431-0.604$ \\
\hline Perceived behavioral control & 0.729 & $0.478-0.612$ \\
\hline Affiliation & 0.796 & $0.570-0.628$ \\
\hline Innovativeness & 0.680 & $0.404-0.545$ \\
\hline Fairness & 0.739 & $0.534-0.642$ \\
\hline Reciprocal relationship & 0.871 & $0.582-0.797$ \\
\hline Reward & 0.673 & $0.507-0.507$ \\
\hline ICT support & 0.822 & $0.569-0.681$ \\
\hline Knowledge sharing intention & 0.830 & $0.580-0.694$ \\
\hline
\end{tabular}

\subsection{Exploratory Factor Analysis (EFA)}

EFA is used to evaluate discriminance value and convergence value of measurement scale. In this research, factor extraction method is Principle Component and rotation method is Promax. Exploratory factor analysis for most factors in the proposed model showed that observation variables are satisfied with the model $(\mathrm{KMO}>0.5$, Bartlett test $\leq$ 0.05 , sig $=0.000$, and Eigenvalue $>1$, total extracted variance > 50\%). However, Affiliation and Innovativeness factor are combined together in 1 factor, and the model should be revised as follows: 


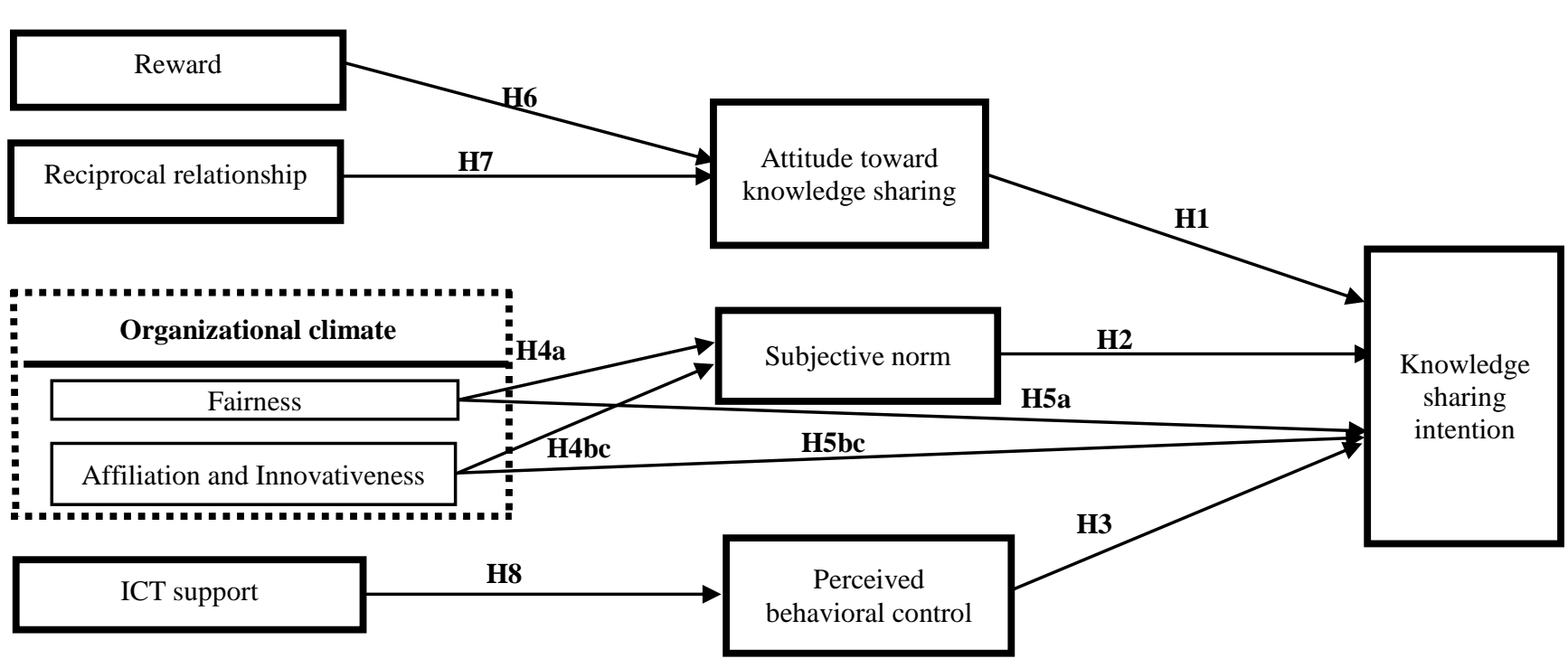

Figure 2. The revised research model

Therefore, hypothesis $\mathrm{H} 4 \mathrm{~b}$ and $\mathrm{H} 4 \mathrm{c}, \mathrm{H} 5 \mathrm{~b}$ and $\mathrm{H} 5 \mathrm{c}$ should be combined together also. The revised hypothesis statement will be:

Hypothesis H4bc: Affiliation and Innovativeness of organizational climate has a positive impact on subjective norm.

Hypothesis H5bc: Affiliation and Innovativeness of organizational climate has a positive impact on knowledge sharing intention.

\subsection{Correlation analysis}

Based on correlation analysis result, Pearson coefficients showed that all independent variables have a strong relationship with dependent variable at 5\% significant level. So, they could be used for regression analysis.

\subsection{Regression analysis}

The regression method is Enter method to analyze relationship between independent factors and dependent factor. The regression analysis result could be summarized in the following table.

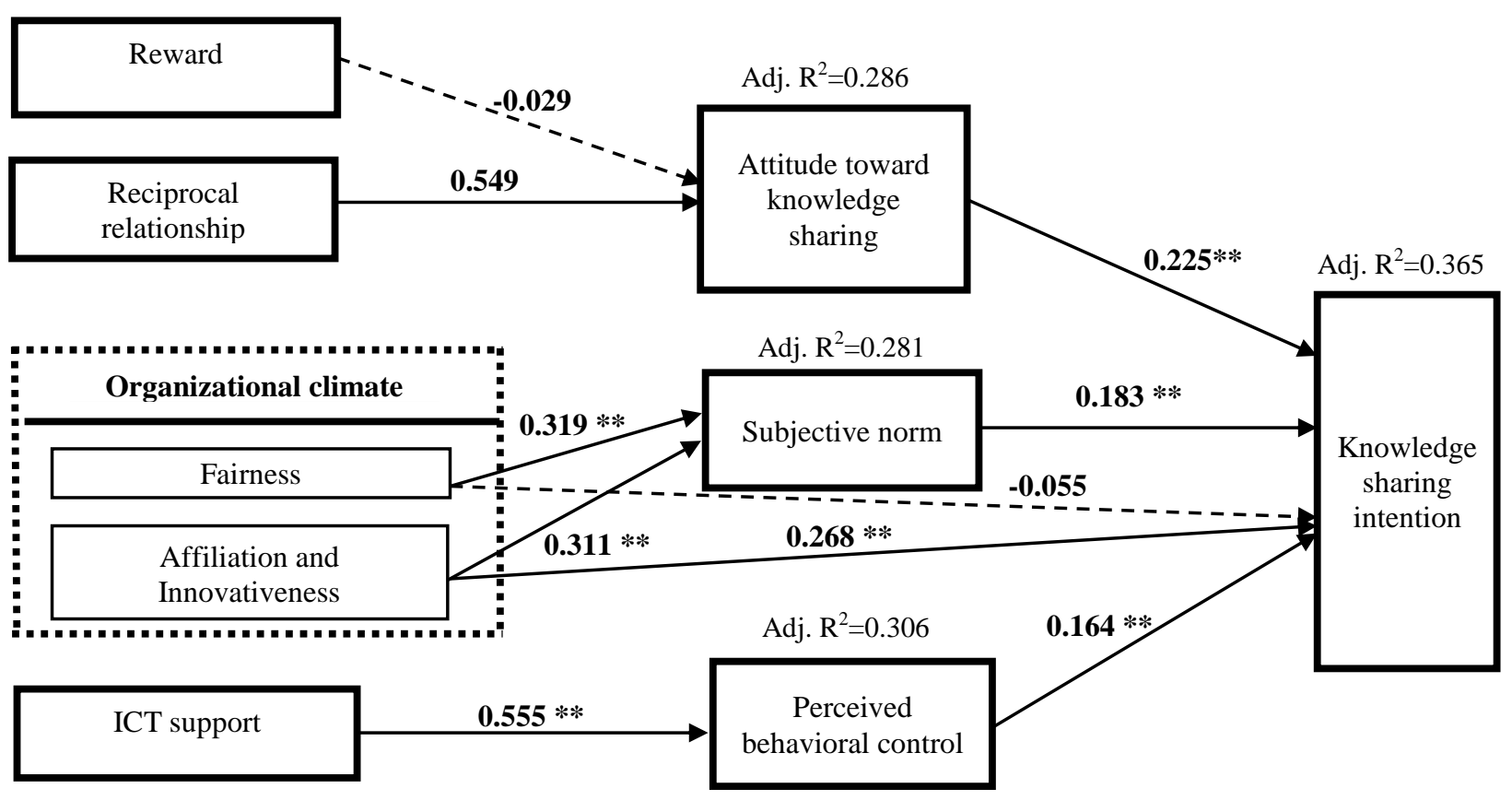

Figure 3. The summarized result of multiple regression analysis 


\subsection{Hypothesis test}

Based on regression analysis result, the conclusion for hypothesis test could be summarized in following table.

\section{Table 3}

Hypothesis evaluation results

\begin{tabular}{|l|c|c|}
\hline \multicolumn{1}{|c|}{ Hypothesis } & Beta & Result \\
\hline $\begin{array}{l}\text { H1: Attitude toward knowledge sharing has a positive impact on } \\
\text { knowledge sharing intention }\end{array}$ & $0.225^{* *}$ & Supported \\
\hline $\begin{array}{l}\text { H2: } \text { Subjective norm has a positive impact on knowledge sharing } \\
\text { intention }\end{array}$ & $0.183^{* *}$ & Supported \\
\hline $\begin{array}{l}\text { H3: Perceived behavioral control has a positive impact on knowledge } \\
\text { sharing intention }\end{array}$ & $0.164^{* *}$ & Supported \\
\hline $\begin{array}{l}\text { H4a: Fairness of organizational climate has a positive impact on } \\
\text { subjective norm }\end{array}$ & $0.319^{* *}$ & Supported \\
\hline $\begin{array}{l}\text { H4bc: Affiliation \& Innovativeness of organizational climate has a } \\
\text { positive impact on subjective norm }\end{array}$ & $0.311^{* *}$ & Supported \\
\hline $\begin{array}{l}\text { H5a: Fairness of organizational climate has a positive impact on } \\
\text { knowledge sharing intention }\end{array}$ & -0.055 & Not \\
\hline $\begin{array}{l}\text { H5bc: Affiliation \& Innovativeness of organizational climate has a } \\
\text { positive impact on knowledge sharing intention }\end{array}$ & $0.268^{* *}$ & Supported \\
\hline $\begin{array}{l}\text { H6: Reward has a positive impact on attitude toward knowledge } \\
\text { sharing }\end{array}$ & -0.029 & Not \\
\hline $\begin{array}{l}\text { H7: Reciprocal relationship has a positive impact on attitude toward } \\
\text { knowledge sharing }\end{array}$ & $0.549^{* *}$ & Supported \\
\hline $\begin{array}{l}\text { H8: ICT support has a positive impact on perceived behavioral } \\
\text { control of knowledge sharing }\end{array}$ & $0.555^{* *}$ & Supported \\
\hline
\end{tabular}

\subsection{ANOVA and $t$-Test}

One-way ANOVA and t-test method are used to test the differences in knowledge sharing intention of IT employees by demographic factors, such as: gender, age, educational level, year of working, and position.

Analysis result of Test of Homogeneity of Variances for gender, age, educational level, year of working showed that Sig. > 0.05. Therefore, the variance of "knowledge sharing intention" is not difference between groups. ANOVA could be used for further analysis. The ANOVA analysis result for all of above factors has sig. $>0.05$, so, there is no difference in knowledge sharing intention between different groups by gender, age, educational level, year of working.

By position, 2 groups will be analyzed including: employees and managers (group leader, functional manager, board of management). The analysis result of Test of Homogeneity of Variances showed that Sig = 0.95> 0.05. Therefore, the variance of "knowledge sharing intention" is not difference between 2 groups. ANOVA could be used for further analysis. The ANOVA analysis result has sig. $=0.011<0.05$, so, there is a difference in knowledge sharing 
intention between 2 employees and managers. According to Mean Plot diagram, manager group has more knowledge sharing intention than employee group. Because the managers often have more information and knowledge than their employees, it is easy to understand why they need to share knowledge with other people in their group to fulfill their responsibility.

\subsection{Discussion}

According to analysis result, Affiliation \& Innovativeness has a highest impact on knowledge sharing intention of IT employees (beta=0.268). Other factors have a positive impact on knowledge sharing intention by descending order including: attitude toward knowledge sharing (beta $=0.225$ ), subjective norm (beta $=0.183$ ), perceived behavioral control (beta $=0.164)$. This result is similar to previous researches. However, there are some differences as follows:

- H6 is not supported. This means reward has no impact on attitude toward knowledge sharing. This result is different from Bock et al. (2005), where there is a negative impact of reward on knowledge sharing intention. In Vietnam context, IT employees are rewarded for their productivity rather than on knowledge sharing, so that, this affection is not significant. However, previous research showed that long-term reward has positive impact, but short-term reward has negative impact on knowledge sharing intention. Therefore, managers of IT companies should use reward policy carefully in order to raise knowledge sharing intention.

- H5a is not supported. This means fairness has no impact on knowledge sharing intention of IT employees in Vietnam. This result is different from previous researches (Bock et al., 2005; Joseph \& Jacob, 2011). This result showed that IT employees in Vietnam are not believed in the fairness of current evaluation method. Suitable KPIs for evaluating their effort in knowledge sharing should be added for changing this situation.

- ICT support is a new factor added in this research, and has a significant impact on perceived behavioral control, which will contribute to knowledge sharing intention of IT employees. Therefore, managers of IT companies should pay attention to ICT solution to support collaboration and knowledge sharing between employees.

\section{Conclusion \& Implications}

In general, based on Theory of Planned Behavior (TPB), an integrated research model has been proposed for evaluating the impact of psychological factors, organization climate and ICT support on knowledge sharing intention of IT employees. Based on analysis result, the factor affecting on knowledge sharing intention of IT employees in Vietnam is sorted by descending order, including: Affiliation and innovativeness, Attitude towards knowledge, Subjective norms, and Perceived behavioral control. Besides, the knowledge sharing intention of employees is also indirectly affected by factors, such as: reciprocal relationship, fairness, and ICT support.

Besides, the ANOVA analysis result shows that there is a difference of knowledge sharing intention between managers and employees. Therefore, managers of IT employees should have some policies to encourage knowledge sharing between employees (create a sharing context, training and coaching) and play a role/model for facilitating knowledge sharing behavior.

Based on this result, some recommendations for improving knowledge sharing intention of IT employees could be suggested as follows:

- Creating an innovative and open organizational climate for encouraging knowledge sharing;

- Applying suitable KPIs for evaluating employees' effort in knowledge sharing;

- Strengthening the relationship between employees by team work and team building activities;

- Applying ICT platform (hardware/ software) to support communication, 
collaboration and to make it easy for knowledge sharing between employees; and

- Focusing on training and coaching for improving productivity and knowledge sharing capability.

There are still some limitations of this research, such as: small sample size, convenience sampling method, limited in regression analysis method.
Some implications for future research could be summarized as follows:

- Increasing sample size and apply better sampling method;

- Applying SEM/ AMOS for analyzing inter-relationship between various factors; and

- Making a comparison between IT industry and other knowledge intensive industries

Acknowledgement: This research is funded by Bach Khoa University (VNU-HCM) under grant number T-QLCN2016-99.

\section{References}

Alamgir, R., \& Ahmed, S. (2011). ICT Enabled Knowledge Sharing-Impact of ICT on Knowledge Sharing Barriers: The Case of Avanade. Retrieved from: http://www.diva-portal.org/

Ajzen, I. (1991). The theory of planned behavior. Organizational behavior and human decision processes, 50(2), 179-211.

Bao-moi (2013). Nghề nào nhiều nhân viên bỏ việc nhất trong năm 2012? Retrieved from: http://www.baomoi.com/

Bock, G. W., Zmud, R. W., Kim, Y. G., \& Lee, J. N. (2005). Behavioral intention formation in knowledge sharing: Examining the roles of extrinsic motivators, social-psychological forces, and organizational climate. MIS quarterly, 87-111.

Bock, G. W., \& Kim, Y. G. (2001). Breaking the myths of rewards: An exploratory study of attitudes about knowledge sharing. Pacis 2001 proceedings, 78.

Borges, R. (2012). Tacit knowledge sharing between IT workers: The role of organizational culture, personality, and social environment. Management Research Review, 36(1), 89-108.

Castro, M. L., \& Martins, N. (2010). The relationship between organisational climate and employee satisfaction in a South African information and technology organization. SA Journal of Industrial Psychology, 36(1), 1-9.

Choi, B., Lee, H. (2002). Knowledge management strategy and its link to knowledge creation process. Expert Systems with Applications, 23, 173-187.

Dalkir, K. (2005). Knowledge management in theory and practice. Routledge.

Dong, G., Liem, C. G., \& Grossman, M. (2010). Knowledge-sharing intention in Vietnamese organizations. VINE, 40(3/4), 262-276.

Hair, J. F., Black, W. C., Babin, B. J., Anderson, R. E., \& Tatham, R. L. (2006). Multivariate data analysis. Upper Saddle River, NJ: Pearson Prentice Hall.

Hendriks, P. (1999). Why share knowledge? The influence of ICT on the motivation for knowledge sharing. Knowledge and process management, 6(2), 91-100.

Hoang, T., \& Chu, N.M.N. (2008). Phân tích dĩ liệu nghiên cúu với SPSS, tập 1, tập 2. NXB Hồng Đức.

Joseph, B., \& Jacob, M. (2011). Knowledge sharing intentions among IT professionals in India. In Information Intelligence, Systems, Technology and Management (pp. 23-31). Springer Berlin Heidelberg.

Le, T.H. (2012). Tổng quan về tình hình phát triển nhân lực CNTT-TT của Tp.HCM trong giai đoạn 2008-2012; Dự thảo Chương trình phát triển nguồn nhân lực CNTT-TT thành phố giai đoạn 2012-2015. Retrieved from: http://qtsc.com.vn/.

Nonaka, I., \& Takeuchi, H. (1995). The knowledge-creating company: How Japanese companies create the dynamics of innovation. Oxford university press. 
Patterson, M. G., West, M. A., Shackleton, V. J., Dawson, J. F., Lawthom, R., Maitlis, S., \& Wallace, A. M. (2005). Validating the organizational climate measure: links to managerial practices, productivity and innovation. Journal of organizational behavior, 26(4), 379-408.

PCWorld (2008). Quản trị tri thức - Tầm nhìn lớn của lãnh đạo. Retrieved from: http://www.pcworld.com.vn/

Thoi-bao vi-tinh Sai-Gon (2013). Phụ nữ trong thế giới công nghệ. Retrieved from: http://tbvtsg.com.vn/

Pham, Q.T. (2013). Apply KM and SNS for Improving Labor Productivity of Vietnamese SME. Covenant Journal of Informatics and Communication Technology, 1 (1).

Pham, Q.T. (2016). Giáo trình Quản lý Tri thức. NXB. Xây Dựng.

Pham, Q.T., Hara, Y. (2011). KM approach for improving the labor productivity of Vietnamese enterprises. International Journal of Knowledge Management, 7(3).

Polanyi, M. (1966). The tacit dimension. Peter Smith, MA: Gloucester.

Serban, A. M., \& Luan, J. (2002). Overview of knowledge management. New Directions for Institutional Research, 2002(113), 5-16.

Tran, T.L.P. \& Pham, N.T. (2011). Yếu tố tác động ý định CSTT của bác sĩ trong bệnh viện - tiếp cận theo lý thuyết hành vi hoạch định TPB. Tạp chí Phát triển Khoa học và Công nghệ, 14(Q2), 80-88.

Tsai, M. T., Chang, H. C., Cheng, N. C., \& Lien, C. C. (2013). Understanding IT professionals' knowledge sharing intention through KMS: a social exchange perspective. Quality \& Quantity, 47(5), 2739-2753.

Wiig, K. (1993). Knowledge management foundations. Arlington, TX: Schema Press.

Zhang, P., \& Ng, F. F. (2013). Explaining knowledge-sharing intention in construction teams in Hong Kong. Journal of Construction Engineering and Management, 139(3), 280-293.

Zhang, J., \& Liu, Y. (2010). Organizational climate and its effects on organizational variables: An empirical study. International Journal of Psychological Studies, 2(2), 189-201. 